Journal of Food Technology 10 (2): 39-45, 2012

ISSN: $1684-8462$

(C) Medwell Journals, 2012

\title{
Phenolic Acids and Flavonoids Profiles of Some Turkish Honeydew and Floral Honeys
}

\author{
${ }^{1}$ Mohammed Ishaq Haroun, ${ }^{2}$ Ender S. Poyrazoglu, ${ }^{2}$ Nevzat Konar and ${ }^{2}$ Nevzat Artik \\ ${ }^{1}$ Faculty of Agriculture, Zalingie University, Western Darfur State, Zalingie, Sudan \\ ${ }^{2}$ Department of Food Engineering, Faculty of Engineering, Ankara University, \\ 06110 Diskapi Ankara, Turkey
}

\begin{abstract}
To characterize honeys of different botanical origin produced in Turkey, phenolic acids and flavonoids profiles were identified by HPLC. Phenolic acids such as caffeic and p-coumaric and flavonoids such as pinocembrin and chrysin were detected in all the samples of this study. All the honeydew (pine and oak) honeys contained protocatechuic acid at significant concentrations. In contrast, almost all the floral honey samples were devoid of protocatechuic acid. Hence, this compound could be botanical marker of honeydew honeys. The oak honey contained significant concentration of ellagic acid $(336.8 \mu \mathrm{g} / 100 \mathrm{~g})$. Therefore, this honeydew could be differentiated from pine honeydews by ellagic acid. On the other hand, the flavonoid kaempferol which was never detected in the honeydew honeys used in this study was detected in many floral honeys such as cotton, yayla and multifloral. Therefore, kaempferol could be a marker for some floral types of honeys. Most of the cotton honey samples contained a flavonoid called as quercetin. But they were devoid of syringic and ferulic acids. The methyl syringate was detected in highest amounts in most of the multifloral honeys and in significant concentrations in yayla honeys. The sunflower honeys were inconsistent in phenolic compounds profile. Most of the sunflower honey samples were contained quercetin. One of sunflower (Sample code: SFH09) honey samples contained myricetin in significant amount $(85.2 \mu \mathrm{g} / 100 \mathrm{~g})$.
\end{abstract}

Key words: Honey, phenolic acids, flavonoids, HPLC, honeydew, multifloral

\section{INTRODUCTION}

The production and supply of honey is lower than the market demands in some regions. Therefore, it is frequently adulterated with relatively cheap high-fructose corn syrup (Swallow and Low, 1990). For this reason authentication of honey by the determination of botanical origin is very important. Characterization of botanical origin of commercial honeys is a hard task initiated in Europe in response to consumers' demand. Those have demanded, not only a basic quality level but also a clear determination of geographical and botanical origin (European Union, 2001; Terrab et al., 2004). Determination of honey adulteration is difficult and depends on the composition of honey or on the presence of specific component in the adulterant. Traditionally, the floral source of a honey has been identified by the analysis of pollen present in the honey. This method is based on the identification of pollen by microscopic examination. It requires a very experienced analyst, it is very time consuming and depends on the experts ability and judgments (Howells, 1969). However, Tan et al. (1989) reported that chemical approaches might be more accurate and easily undertaken in the characterization of the floral source of a honey. The use of phenolic compound analysis in the identification of honeys has been reported by Amiot et al. (1989) and has since been used as a tool for studying the floral and geographical origins of honeys. In addition, determination of type and/or amount of a honey polyphenols is very important. Because a honey polyphenols contributes to some honey quality parameters such as bitterness and color (Amiot et al., 1989). Also honey phenolic compounds, especially the flavoniods contribute to a wide range of biological functions such as antioxidant activity, antibacterial, anticancerogenic and antiallergic (Bogdanov, 1984; Cook and Samman, 1996).

The authentication of geographical origin of honeys was investigated by various researchers. The flavonoid profiles of various honey samples from different regions in the world were studied by Tomas-Barberan et al. (1993). In general, the honeys from the North Hemisphere where poplars (the source of propolis) are native and honeys from Central and South America and New Zealand where

Corresponding Author: Mohammed Ishaq Haroun, Faculty of Agriculture, Zalingie University, Western Darfur State, Zalingie, Sudan 
non-native poplar trees have been planted, show flavonoid profiles characterized by the presence of propolis flavonoids such as pinocembrin, pinobanksin and chrysin. In contras, honeys sourced from most equatorial regions and Australia are devoid propolis derived flavonoids but contain flavonoids from other parts of the plants such as nectar and pollen. The determination of the floral origin is recognized as a very important task in honey quality control (Ferreres et al., 1994a; Guyot et al., 1998, 1999). The phenolic profiles of different types of honeys were investigated in many researches. For example, the flavonoid profile of sunflower honey (Amiot et al., 1989; Sabatier et al., 1992; Berahia et al., 1993; Tomas-Barberan et al., 2001; Yao et al., 2004a), citrus honey (Ferreres et al., 1993; Martos et al., 1997) was determined. The phenolic compound profiles of chestnut (Castanea sativa) honey (Andrade et al., 1997a), thyme honey (Andrade et al., 1997b; Martos et al., 1997), heather (Calluna vulgaris L.) honey (Ferreres et al., 1994b; Anklam, 1998; Weston et al., 2000) were investigated. Eucalyptus honey is a common commercial honey that produced in different regions of the world and its phenolic profile is studied intensively and showed some variations in the amounts and patterns (Martos et al., 1997, 2000a, b; Yao et al., 2004b). New Zealand Manuka (Leptospermum scoparium) honey is well known by its antibacterial activity (Weston et al., 1999). This honey in different studies showed different phenolic profiles (Weston et al., 1999 , 2000).
Available literature, concerning the researches carried out to characterize Turkish honeys indicates that there is no sufficient data about phenolic acids and flavanoiods. The purpose of this study was to determine the phenolic acids and flavanoids profiles of the different botanical origin of honeys produced in Turkey.

\section{MATERIALS AND METHODS}

Honey samples: Total of 27 honey samples of the main two types of honeys, namely, honeydew and floral honeys produced in different regions of Turkey were used. The honeydew honeys were pine (Pinus sp.) $(\mathrm{n}=7)$ and oak (quercus) $(\mathrm{n}=1)$ honeys. While the floral honeys were cotton (Gossypium barbadense) $(\mathrm{n}=5)$, chestnut (Castanea $\mathrm{sp}$.) ( $\mathrm{n}=4)$, sunflower (Helianthus annuus) $(n=3)$, yayla (mountain pasture) $(n=3)$, multifloral $(n=4)$ and citrus $(n=1)$. These samples were obtained from different sources; Balparmak Company (Istanbul, Turkey), Fer Company (Ankara, Turkey), Ankara University Agriculture Faculty Animal Science Department (Ankara, Turkey), Honeybee Breeding Association (Ankara, Turkey) and local markets in Ankara, Turkey (Table 1). The honey samples were stored under cold condition (refrigerator) until they were used in the analysis.

Chemical solvents and standards: Distilled water, analytical grade Hydrochloric acid $(\mathrm{HCl})$ and metanol (Merck, Darmstadt, Germany) were used for column chromatography in the extraction of phenolic compounds

Table 1: Group, botanical source and provider of the honey samples

\begin{tabular}{|c|c|c|c|}
\hline Groups & Botanical source & Code & Producer \\
\hline \multirow[t]{7}{*}{$\bar{A}$} & Pine & PNH02 & Balparmak company \\
\hline & & PNH12 & Balparmak company \\
\hline & & PNH16 & Fer company \\
\hline & & $\mathrm{PNH} 24$ & Fer company \\
\hline & & PNH29 & Honeybee Breeding Association \\
\hline & & PNH39 & Honeybee Breeding Association \\
\hline & & PNH45 & Fer company \\
\hline \multirow[t]{5}{*}{ B } & Cotton & CTH06 & Balparmak company \\
\hline & & СТH08 & Balparmak company \\
\hline & & CTH10 & Balparmak company \\
\hline & & CTH11 & Balparmak company \\
\hline & & $\mathrm{CTH} 23$ & Fer company \\
\hline \multirow[t]{4}{*}{$\mathrm{C}$} & Chestnut & $\mathrm{CNH} 26$ & Local market \\
\hline & & $\mathrm{CNH} 27$ & Honeybee Breeding Association \\
\hline & & $\mathrm{CNH} 40$ & Honeybee Breeding Association \\
\hline & & $\mathrm{CNH} 41$ & Honeybee Breeding Association \\
\hline \multirow[t]{3}{*}{$\mathrm{D}$} & Sunflower & SFH05 & Balparmak company \\
\hline & & SFH09 & Balparmak company \\
\hline & & $\mathrm{SFH} 20$ & Fer company \\
\hline \multirow[t]{3}{*}{$\mathrm{E}$} & Yayla (mountain pasture) & YLH21 & Fer company \\
\hline & & YLH22 & Fer company \\
\hline & & YLH42 & Fer company \\
\hline \multirow[t]{4}{*}{$\mathrm{F}$} & Multifloral & MFH13 & Balparmak company \\
\hline & & MFH14 & Balparmak company \\
\hline & & MFH28 & Honeybee Breeding Association \\
\hline & & MFH44 & Fer company \\
\hline $\mathrm{G}$ & Oak (Quercus) & $\mathrm{OKH} 25$ & Animal Science Department \\
\hline$\underline{\mathrm{H}}$ & Citrus & CRH35 & Local market \\
\hline
\end{tabular}


while distilled water and analytical grade diethyl ether were used for rel26 extraction (purification) of phenolic compounds. HPLC grade acetonitrile (Merck, Darmstadt, Germany), distilled water, 85\% phosphoric acid (Merck, Darmstadt, Germany) were used for HPLC analysis. The authentic chemical compounds used for the identification and quantification of phenolic compounds in this study were: protocatechuic acid, caffeic acid, syringic acid, p-coumaric acid, ferulic, ellagic acid, myricetin, quercetin, luteolin, apigenin, kaempferol, pinocembrin, chrysin and acacetin (Merck, Darmstadt, Germany).

Sample extraction: Extraction of honey phenolic compounds was carried out as described previously by Andrade et al. (1997a), Martos et al. (1997, 2000a, b) and Yao et al. (2004a, b). Honey samples (25 g) were thoroughly mixed with five parts of distilled water until completely fluid, adjusted to $\mathrm{pH} 2$ with $\mathrm{HCl}$. Then, the samples were filtered through cotton wool to remove the solid particles. The filtrate was mixed with $40 \mathrm{~g}$ of Amberlite XAD-2 (Supelco, Bellefonte, PA., USA, pore size $9 \mathrm{~nm}$, particle size $0.3-1.2 \mathrm{~mm}$ ) and stirred in magnetic stirrer for $20 \mathrm{~min}$. The Amberlite particles were then packed in a glass column $(25 \times 2 \mathrm{~cm})$ and the column was washed with acidified water $(\mathrm{pH} 2$ with $\mathrm{HCl}, 65 \mathrm{~mL})$ and subsequently rinsed with distilled water $(75 \mathrm{~mL})$ to remove all sugars and other polar constituents of the honey. The phenolic acids and flavonoids were then eluted with methanol $(100 \mathrm{~mL})$. This extract was concentrated to dryness under reduced pressure at $40^{\circ} \mathrm{C}$. The residue was redissolved in distilled water $(5 \mathrm{~mL})$ and extracted with diethyl ether $(5 \times 3 \mathrm{~mL})$. The diethyl ether extracts were combined and diethyl ether was removed by flushing with nitrogen. The dried residue was then redissolved in $1.0 \mathrm{~mL}$ of methanol (HPLC grade) and filtered through $0.45 \mu \mathrm{m}$ membrane and used in HPLC analysis.

HPLC analysis of phenolic compounds: The HPLC analysis of phenolic acids and flavanoids were carried out using Shimadzu class-VP HPLC System (LC-10AD VP), a computer controlled system class VP Software. Separations were carried out on a reversed phase column Teknoroma TR-416056, Tracer Extrasil ODS2 $5 \mu \mathrm{M}$, $12.5 \times 0.4 \mathrm{~cm}$ (TeknoromaA, Barcelona, Spain) using a mobile phase of $1 \%(\mathrm{v} / \mathrm{v})$ aqueous $85 \%$ phosphoric acid (Solvent A) and acetonitrile (Solvent B) at constant solvent flow rate of $1 \mathrm{~mL} \mathrm{~min}{ }^{-1}$. The temperature of the column oven was set at $35^{\circ} \mathrm{C}$. The gradient elution was established as follows: $6 \%$ acetonitrile (Solvent B) flowed through the column isocratically with Solvent A for $7 \mathrm{~min}$; this was increased to $10 \%$ acetonitrile at $30 \mathrm{~min}, 33 \%$ acetonitrile at $70 \mathrm{~min}$. Finally, isocratic elution with $33 \%$ acetonitrile was done until $95 \mathrm{~min}$. The honey extracts were injected manually with Hamilton Sample Lock Syringe, $100 \mu \mathrm{L}$ (Hamilton Company, Reno, Nevada, USA) and the phenolic acids and flavoniods were detected using photodiode detector (SPD-M10A VP) to obtain the UV spectra of the various phenolic compounds. The chromatograms were monitored at 290 and $340 \mathrm{~nm}$ since, the majority of the honey phenolic acids and flavanoids show their UV absorption maxima around these two wavelength (Martos et al., 1997). The flavanoids were quantified by comparison of their peak areas in the HPLC chromatogram against the peak areas of the external standards in the HPLC chromatograms under the same conditions. All samples were injected into the HPLC system in triplicate.

Statistical analysis: The HPLC experiments were performed in triplicate. Quantitative data are expressed as mean.The results were analysed to determine Standard Deviations (SD) by using MS Excel 2007 (Microsoft Corporation, USA).

\section{RESULTS AND DISCUSSION}

The phenolic acids and flavonoids contents of the honey samples used in the study were shown in Table 2. In general, phenolic acids such as caffeic and p-coumaric and flavonoids such as pinocembrin and chrysin were detected in almost all the honey samples used in this study. The presence of antimicrobially active pinocembrin and chrysin in Turkish honeys is very normal. Because, the honeys from regions where poplars (the source of propolis) are native or being planted, show flavonoid profiles of propolis flavonoids such as pinocembrin, pinobanksin and chrysin (Tomas-Barberan et al., 1993).

Honeydew honeys: The protocatechuic acid was detected in all the honey samples of $\mathrm{A}$ and $\mathrm{G}$ (honeydews) in the range of 598.6-163.9 $\mu \mathrm{g} 100 \mathrm{~g}^{-1}$ (Table 2). The protocatechuic acid would be a reliable index in the differentiation of Turkish honeydew honeys from floral honeys. These results are completely in agreement with the findings of Joreg and Sontag (1993) and Steeg and Montag (1988) who reported that the presence of protocatechuic acid enables this honey to be distinguished from other types of honeys. The two types of honeydew, namely, Pine and Oak quercus honeydews could be differentiated by ellagic acid. Since, this compound was detected in significant amount in $\mathrm{G}$ (Oak, quercus) honeydew (336.8 $\mu \mathrm{g} / 100 \mathrm{~g}$ ) and not detected in all the samples of A (pine) honeydews. Ellagic acid was detected only in one sample (KBB30) of 
Table 2: Contents of phenolic acids of some honey dew and floral honeys produced in Turkey Phenolic compound $(\mu \mathrm{g} / 100 \mathrm{~g})^{*}$

\begin{tabular}{|c|c|c|c|c|c|c|c|c|c|c|c|c|c|c|c|c|}
\hline $\begin{array}{l}\text { Group of } \\
\text { honey }\end{array}$ & $\begin{array}{l}\text { Code of } \\
\text { honey }\end{array}$ & ProA & CafA & SyrA. & P-CouA & FerA & $\begin{array}{l}\text { Methy } \\
\text { syri }\end{array}$ & EllA & Myri & Quer & Lute & Apig & Kaem & Pinc & Chry & Acac \\
\hline \multirow[t]{7}{*}{ Pine } & $\mathrm{PNH} 02$ & 598.6 & 94.1 & $\mathrm{ND}$ & 24.2 & 15.5 & $\mathrm{ND}$ & $\mathrm{ND}$ & $\mathrm{ND}$ & 65.7 & $\mathrm{ND}$ & $\mathrm{ND}$ & ND & 17.7 & 27.7 & $\mathrm{ND}$ \\
\hline & PNH12 & 275.8 & 71.5 & 30.1 & 25.3 & 16.6 & 88.4 & ND & ND & ND & ND & ND & ND & 6.21 & 6.37 & ND \\
\hline & PNH16 & 163.9 & 72.5 & 28.7 & 18.7 & 8.92 & 89.9 & ND & ND & ND & ND & ND & ND & 10.8 & 6.43 & ND \\
\hline & PNH24 & 361.9 & 22.7 & 13.5 & 13 & ND & 121.9 & ND & ND & ND & ND & 14.4 & ND & 4.48 & 5.07 & ND \\
\hline & PNH29 & 241.1 & - & ND & 15.7 & 16.2 & 171.8 & ND & ND & ND & ND & ND & ND & 7.36 & 2.69 & ND \\
\hline & PNH39 & 387.6 & 46.1 & 303.4 & 35.5 & 7.36 & 2687 & ND & ND & 16.4 & ND & 16.7 & ND & 6.46 & 7.86 & ND \\
\hline & PNH45 & 358.1 & 2.61 & 7.69 & 3.9 & ND & $\mathrm{ND}$ & ND & ND & ND & ND & ND & ND & 5.23 & 2.82 & ND \\
\hline \multirow[t]{5}{*}{ Cotton } & СTH06 & 91.2 & 821 & $\mathrm{ND}$ & 211.8 & ND & ND & ND & ND & 15.8 & ND & ND & 26.3 & 14.8 & 10.6 & ND \\
\hline & СТH08 & ND & 23.7 & ND & 39.6 & ND & 511.8 & ND & ND & ND & ND & 3.85 & 5.54 & 8.12 & 8.28 & ND \\
\hline & CTH10 & ND & 16 & ND & 57.7 & 7.33 & 134.9 & ND & ND & 7.8 & ND & ND & ND & 3.96 & 5.79 & ND \\
\hline & CTH11 & NI & 28.4 & 8.43 & 31 & ND & 29. & $\mathrm{~N}$ & $\mathrm{~N}$ & 36.8 & & 7.28 & D & 11.5 & 11 & ND \\
\hline & $\mathrm{CTH} 23$ & ND & 7.07 & ND & 18.8 & ND & 35.1 & NI & $\mathrm{N}]$ & 10.2 & ND & NI & ND & 2.63 & 3.73 & ND \\
\hline \multirow[t]{4}{*}{ Chestnut } & $\mathrm{CNH} 26$ & ND & 54.5 & ND & 26 & 25 & 95.8 & $\mathrm{~N}$ & $\mathrm{~N}$ & ND & ND & ND & ND & 32.4 & 33 & ND \\
\hline & $\mathrm{CNH} 27$ & ND & 83 & ND & 280.1 & ND & ND & ND & ND & ND & ND & ND & ND & 8.17 & 11.2 & ND \\
\hline & $\mathrm{CNH} 40$ & ND & 18.5 & ND & 134.4 & 4.3 & ND & ND & ND & ND & ND & ND & ND & 8.03 & 8.9 & ND \\
\hline & CNH41 & NI & 3 & $\mathrm{~N}$ & 4 & 13.2 & ND & $\mathrm{N}$ & $\mathrm{N}$ & $\mathrm{N}$ & ND & $\mathrm{N}$ & D & 17.7 & 8.31 & ND \\
\hline \multirow[t]{3}{*}{ Sunflower } & SFH05 & NI & 40.7 & ND & 8. & 6.7 & ND & NL & $\mathrm{N}$ & 35.1 & ND & ND & ND & 29 & 18.9 & 8.77 \\
\hline & SFH09 & ND & 70.4 & 16.1 & 9.01 & 8.32 & ND & ND & 85.2 & ND & ND & ND & ND & 10 & 5.61 & ND \\
\hline & $\mathrm{SFH} 20$ & 31.9 & 36.6 & ND & 8.88 & 12 & 36.9 & ND & ND & 33.5 & 15.5 & ND & ND & 16.8 & 12.2 & ND \\
\hline \multirow{7}{*}{$\begin{array}{l}\text { Yayla, } \\
\text { mountain } \\
\text { pasture } \\
\text { Multiflora }\end{array}$} & YLH21 & ND & 33.2 & ND & 17.5 & 2.14 & 576.6 & ND & ND & ND & ND & ND & ND & 10.8 & 14.6 & ND \\
\hline & YLH22 & $\mathrm{ND}$ & 35.2 & 30.7 & 22.4 & ND & 280 & ND & ND & 6.18 & ND & $\mathrm{N}$ & 8.56 & 8.4 & 9.52 & ND \\
\hline & YLH42 & NI & 29. & ND & 22 & 1.5 & 395.6 & $\mathrm{~N}$ & $\mathrm{~N}]$ & NI & $\mathrm{N}$ & 7.94 & 10.1 & 18.9 & 13.6 & ND \\
\hline & MFH13 & ND & 42.5 & 44.8 & 49.3 & 9.52 & 1095 & $\mathrm{~N}$ & ND & 25.3 & ND & 11.3 & ND & 7.68 & 12.7 & ND \\
\hline & MFH14 & ND & 17.2 & 107.8 & 16.2 & ND & 1767 & ND & ND & 7.98 & ND & 81.2 & ND & 8.48 & 8.38 & 7.37 \\
\hline & MFH28 & ND & 18.7 & 72 & 63.3 & 6.14 & 12,483 & ND & ND & ND & ND & ND & 65.8 & 10.4 & 8.3 & ND \\
\hline & MFH44 & ND & 19.2 & $\mathrm{ND}$ & 9.96 & $\mathrm{ND}$ & 130.8 & $\mathrm{ND}$ & ND & ND & ND & $\mathrm{ND}$ & 5.25 & 8.5 & 4.25 & $\mathrm{ND}$ \\
\hline 0 & OKH25 & 262. & 256.4 & 40.8 & 68.2 & 57. & ND & 336.8 & NI & 38.2 & ND & NI & ND & 86.8 & 77 & 4.54 \\
\hline Citrus & CRH35 & ND & 52.2 & 154.1 & 25.9 & 20.1 & 416.9 & ND & ND & ND & 9.2 & 28.7 & $\mathrm{ND}$ & 39.7 & 21.2 & 3.41 \\
\hline
\end{tabular}

All experiments were performed in triplicates. All data are given as mean. ND: Not Determined, ProA: Protocatechuic Acid, CafA: Caffeic Acid, SyrA: Syringic Acid, p-CouA: p-Coumaric Acid, FerA: Ferulic Acid, Methy Syri: Methyl Syringate, EllA: Ellagic Acid, Myri: Myricetin, Quer: Quercetin, Lute: Luteolin, Apig: Apigenin, Kaem: Kaempferol, Pinc: Pinocembrin, Chry: Chrysin, Acac: Acacetin

Group I at very low concentration. Also acacetin was detected in Oak quercus honeydew $(\mathrm{G})$ in low concentration and not detected in Group A (pine) honeys. According to these results, the pine honeydews phenolic profile contained phenolic acids such as protocatechuic, cafeic, syringic, p-coumaric, ferulic, methylsyringate and flavonoids such as pinocembrin and chrysin (Fig. 1). In addition, quercetin and apigenin were detected in 2 samples out of 7 pine honeys. While Oak quercus honeydew $(\mathrm{G})$ contained phenolic profile comprising protocatechuic, cafeic, syringic, p-coumaric, ferulic, ellagic acids and quercetin, pinocembrin, chrysin and acacetin flavonoid (Fig. 1). The presence of ellagic acid in honeydew honeys was never reported in the previous researchers. But it was found in many heather honeys in significant concentrations in New Zealand Manuka honeys (Yao et al., 2003) and Australian Eucalyptus honeys (Yao et al., 2004a, b).

Floral honeys: The samples of cotton honeys were contained phenolic compunds such as caffeic acid, p-coumaric acid, methyl syringate, quercetin, pinocembrin and chrysin in general and both apigenin and kaempferol were detected in 2 samples out of 5 in various amounts
(Fig. 1). It is clear that some samples of cotton honey were contained the flavonoid kaempferol which have never detected in honeydew honeys. In addition, devoid of phenolic acids such as syringic and ferulic acids that detected almost in all the honeydew honeys and in many floral honeys and as well as protocatechuic acid. There is no information concerning phenolic compounds profile of cotton honey in the previous researchers.

The phenolic compounds such as caffeic acid, p-coumaric acid, ferulic acid, pinocembrin and chrysin were detected in chesnut honeys. Unfortunately, most of the peaks on the chromatograms of this type of honeys remained unidentified (Fig. 1). Because their retention times and UV spectra were different from the retention times and UV spectra of the standards used in this study. It is reported that chestnut honeys are rich in phenolic acids and poor in flavonoids (Andrade et al., 1997b). The result obtained in the study, to some extend is similar to the findings of D'Arcy (2005) who reported that the hydroxycinnamates, caffeic, p-coumaric and ferulic acids are dominant in chestnut, sunflower, lavender and acacia honeys.

The phenolic profiles of sunflower honeys were inconsistent. The phenolic compounds such as caffeic 

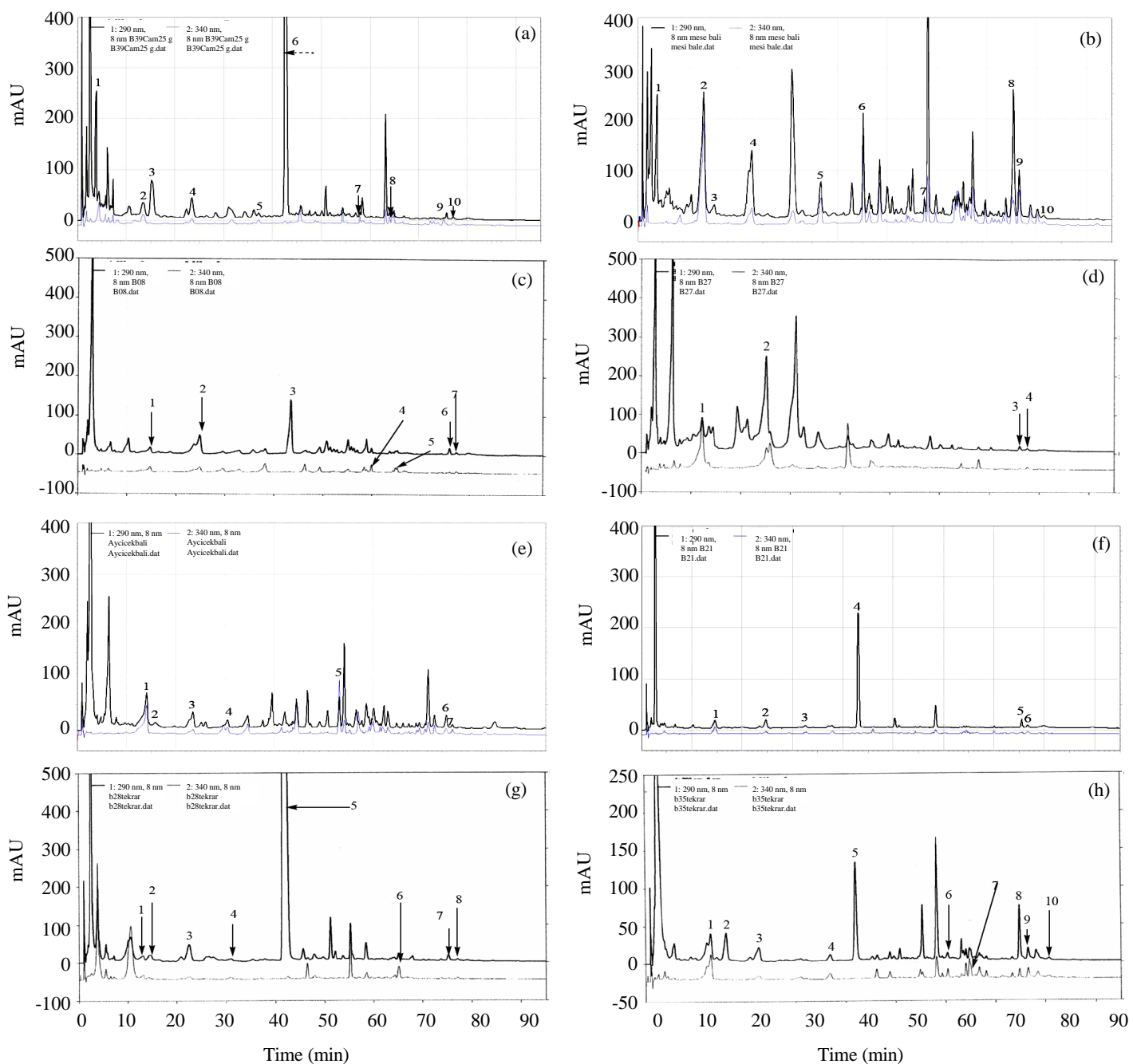

Fig. 1: Various HPLC chromatogram of phenolic compounds (a: pine honey; b: Oak (quercus) honey, c: cotton (Gossypium barbadense) honey; d: chestnut honey; e: sunflower honey; f: yayla (mountain pasture) honey; g: multifloral honey; h: citrus honey), Sample a (1: Protocatechuic acid; 2: caffeic acid; 3: syringic acid; 4: p-coumaric acid; 5: ferulic acid; 6: methyl syringate; 7: quercetin; 8: apigenin; 9: pinocembrin; 10: chrysin), Sample b (1: Protocatechuic acid; 2: caffeic acid; 3: syringic acid; 4: p-coumaric acid; 5: ferulik acid; 6: ellagic acid; 7: quercetin; 8: pinocembrin; 9: chrysin; 10: acacetin), Sample c (1: Caffeic acid; 2: p-coumaric acid; 3: methyl syringate; 4: apigenin; 5: kaempferol; 6: pinocembrin; 7: chrysin), Sample d (1: Caffeic acid; 2: p-coumaric acid; 3: pinocembrin; 4: chrysin), Sample e (1: Caffeic acid; 2: syringic acid; 3: p-coumaric acid; 4: ferulic acid; 5: myricetin; 6: pinocembrin; 7: chrysin), Sample f (1: Caffeic acid; 2: p-coumaric acid; 3: ferulic acid; 4: methyl syringate; 5 : pinocembrin; 6: chrysin), Sample g (1: Caffeic acid; 2: syringic acid; 3: p-coumaric acid; 4: ferulic acid; 5: methyl syringate; 6: kaempferol; 7: pinocembrin; 8: chrysin), Sample h (1: Caffeic acid; 2: syringic acid; 3: p-coumaric acid; 4: ferulik acid; 5: methyl syringate; 6: luteolin; 7: apigenin; 8: pinocembrin; 9: chrysin; 10: acacetin)

acid, p-coumaric acid, ferulic acid, pinocembrin and chrysin were detected in all the samples of this group. In addition to these, one of samples contained quercetin and acacetin. Another sample contained syringic acid myricetin in significant amount $(85.2 \mu \mathrm{g} / 100 \mathrm{~g})$ (Fig. 1). Among the honey samples used in this study, the flavonoid myricetin was detected only in this sample. Also another sample of sunflower honeys contained protocatechuic acid, methyl syringate, quercetin and luteolin. The flavonoid luteolin was detected only in two samples of this study, one of sunflower honeys and one of citrus honeys. The sunflower honeys used in this 
study were very poor in the number of flavonoids and the amounts. But they contained some poplar-derived flavonoids such as pinocembrin and chrysin. The phenolic compounds of sunflower honey from different regions were very variable (Sabatier et al., 1992; Martos et al., 1997; Yao et al., 2004a).

The phenolic profiles of the samples of Yayla (mountain pasture) honeys consisted caffeic acid, p-coumaric acid, ferulic acid (very low), methylsyringate, kaempferol, inocembrin and chrysin in general (Fig. 1). In addition to these, one sample contained syringic acid and low amount of quercetin while another sample contained low concentration of apigenin. It is clear that methyl syringate was found in significant amounts in this type of honey $(280.0-576.6 \mu \mathrm{g} / 100 \mathrm{~g})$.

The multifloral honeys showed phenolic profile containing caffeic acid, syringic acid, p-coumaric acid, methyl syringate, pinocembrin and chrysin with methyl syringate dominating. In addition to these, ferulic acid, quercetin, apigenin and kaempferol were detected in 2 samples out 4 samples of this type of honey (Fig. 1). Extremely higher amount of methyl syringate was detected in a multifloral honey sample $(12.5 \mu \mathrm{g} / 100 \mathrm{~g})$, it was the highest phenolic compound detected in this study. This compound is reported to occur in many types of honeys in various amounts. It is considered as floral marker of New Zealand Manuka (Leptospermum scoparium) honey since, methyl syringate constituted approximately $70 \%(\mathrm{w} / \mathrm{w})$ of the phenolic content of this honey (Weston et al., 2000). In the case of the study, methyl syringate was detected in most of the samples of this study but it was highest in the multifloral honeys. However, at least one sample out of the 7 samples of pine honeydew honeys contained too high concentration of methyl syringate $(2,687 \mu \mathrm{g} / 100 \mathrm{~g})$. Up to this point, in this study, the flavonoid kaempferol was detected only in the floral honeys such as cotton, yayla and multifloral and never detected in honeydew honeys. Accordingly, the kaempferol would be a marker for some floral honeys. In addition, it would help in differentiation between chestnut and sunflower honeys from the other types of floral honeys. Since, kaempferol was not detected in chestnut and sunflower honeys.

\section{CONCLUSION}

Only one sample of citrus honeywas used in this study. The phenolic compounds, caffeic acid, syringic acid, p-coumaric acid, ferulic acid, methyl syringate, luteolin, apigenin, pinocembrin, chrysin and acacetin were detected. In the term of flavonoids, this profile is different from that found by Martos et al. (1997) in
Tunisian citrus honeys. The phenolic acids detected in this study are similar to that of multifloral honeys. But it was different from the phenolic acids of the other floral honeys.

\section{REFERENCES}

Amiot, M.J., S. Aubert, M. Gonnet and M. Tacchini, 1989. The phenolic compounds in honeys: Preliminary study upon identification and family quantification. Apidologie, 20: 115-125.

Andrade, P., F. Ferreres and M.T. Amaral, 1997b. Analysis of honey phenolic acids by HPLC, its application to honey botanical characterization. J. Liquid Chromatogr. Related Technol., 20: 2281-2288.

Andrade, P., F. Ferreres, M.I. Gil and F.A. TomasBarberan, 1997a. Determination of phenolic compounds in honeys with different floral origin by capillary zone electrophoresis. Food Chem., 60: $79-84$.

Anklam, E., 1998. A review of the analytical methods to determine the geographical and botanical origin of honey. Food Chem., 63: 549-562.

Berahia, T., C. Cerrati, S. Sabatier and M.J. Amiot, 1993. Gas chromatography-mass spectrometry analysis of flavonoids in honey. Sci. Aliment, 13: $15-24$.

Bogdanov, S., 1984. Characterization of antibacterial substances in honey. Lebensm. Wiss. Technol., 17: 74-76.

Cook, N.C. and S. Samman, 1996. Flavonoids-chemistry, metabolism, cardioprotective effects and dietary sources. J. Nutr. Biochem., 7: 66-76.

D'Arcy, B.R., 2005. Antioxidants in Australian floral honeys: Identification of health-enhancing nutrient components: A report for the rural industries research and development corporation. Rural Industries Research and Development Corporation Publication No. 05/040, RIRDC Project No. UQ-102A, Australia, pp: 94. https://rirdc.infoservices.com.au/ downloads/05-040.

European Union, 2001. Council directive 2001/110/EC of 20 December 2001 relating to honey. The Council of European Union, pp: 47-52. http://www.wipo.int/ wipolex/en/details.jsp?id=10333.

Ferreres, F., C. Garcia-Viguera, F. Tomas-Lorente and F.A. Tomas-Barberan, 1993. Hesperetin: A marker of the floral origin of citrus honey. J. Sci. Food Agric., 61: 121-123.

Ferreres, F., F.A. Tomas-Barberan, C. Soler, C. GarciaViguera, A. Ortiz and F. Tomas-Lorente, 1994a. A simple extractive technique for honey flavonoids HPLC analysis. Apidologie, 25: 21-30. 
Ferreres, F., P. Andrade and F.A. Tomas-Barberan, 1994b. Flavonoids from Portuguese heather honey. J. Food Control Res. A, 199: 32-37.

Guyot, C., A. Bouseta, V. Scheirman and S. Collin, 1998. Floral origin markers of chestnut and lime tree honeys. J. Agric. Food Chem., 46: 625-633.

Guyot, C., V. Scheirman and S. Collin, 1999. Floral origin markers of heather honeys: Calluna vulgaris and Erica arborea. Food Chem., 64: 3-11.

Howells, V.W., 1969. Some reflections on the pollen analysis of honey. J. Assoc. Public Anal., 7: 88-93.

Joreg, E. and G. Sontag, 1993. Multichannel coulometric detection coupled with liquid chromatography for determination of phenolic esters. J. Chromatogr., 635: 137-142.

Martos, I., F. Ferreres and F.A. Tomas-Barberan, 2000a. Identification of flavonoid markers for the botanical origin of Eucalyptus honey. J. Agric. Food Chem., 48: 1498-1502.

Martos, I., F. Ferreres, L. Yao, B.R. D'Arcy, N. Caffin and F.A. Tomas-Barberan, 2000b. Flavonoids in monospecific Eucalyptus honeys from Australia. J. Agric. Food Chem., 48: 4744-4748.

Martos, I., M. Cossentini, M., F. Ferreres and F.A. Tomas-Barberan, 1997. Flavonoid composition of Tunisian honeys and propolis. J. Agric. Food Chem., 45: 2824-2829.

Sabatier, S., M.J. Amiot, M. Tacchini and S. Aubert, 1992. Identification of flavonoids in sunflower honey. J. Food Sic., 57: 773-777.

Steeg, E. and A. Montag, 1988. Quantitative determination of aromatic carboxylic acids in honey. J. Food Control Res. A, 187: 115-120.

Swallow, K.W. and N.H. Low, 1990. Detection of adulteration of honey with high fructose syrup and beet invert sugar using HPLC. Proceedings of the 33rd Annual Conference of the Canadian Institute of Food Science and Technology, June 3-6, 1990, Saskatoon, Saskatchewan, Canada.
Tan, S.T., A.L. Wilkins, P.C. Molan, P.T. Holands and M. Acid, 1989. A chemical approach to the determination of floral sources of New Zealand honeys. J. Apicult. Res., 28: 212-222.

Terrab, A., A.F. Recamales, D. Hernanz and F.J. Heredia, 2004. Characterisation of Spanish thyme honeys by their physicochemical characteristics and mineral contents. Food Chem., 88: 537-542.

Tomas-Barberan, F.A., F. Ferreres, C. Garcia-Viguera and F. Tomas-Lorente, 1993. Flavonoids in honey of different geographical origin. J. Food Control Res. A, 196: 38-44.

Tomas-Barberan, F.A., I. Martos, F. Ferreres, B.S. Radovi and E. Anklam, 2001. HPLC flavonoid profiles as markers for the botanical origin of European unifloral honeys. J. Sci. Food Agric., 81: 485-496.

Weston R.J., K.R. Mitchell and K.L. Allen, 1999. Antibacterial phenolic components of New Zealand manuka honey. Food Chem., 64: 295-301.

Weston, R.J., L.K. Brocklebank and Y. Lu, 2000. Identification quantitative levels of antibacterial components of some New Zealand honeys. Food Chem., 70: 427-435.

Yao, L., N. Datta, F.A. Tomas-Barberan, F. Ferreres, I. Martos and R. Singanusong, 2003. Flavonoids phenolic acids abscisic acid in Australian New Zealand Leptospermum honeys. Food Chem., 81: 159-168.

Yao, L., Y. Jiang, R. Singanusong, B. D'Arcy, N. Datta, N. Caffin and K. Raymont, 2004a. Flavonoids in Australian Melaleuca, Guioa, Lophostemon, Banksia and Helianthushoneys and their potential for floral authentication. Food Res. Int., 37: 166-174.

Yao, L., Y. Jiang, R. Singanusong, N. Datta and K. Raymont, 2004b. Phenolic acids and abscisic acid in Australian Eucalyptus honey and their potential for floral authentication. Food Chem., 86: 169-177. 